\title{
¿En qué sentido es objetiva la noción de incumplimiento del soft law?*
}

\author{
Recibido: 17 de abril de 2017 • Aprobado: 03 de julio de 2018 \\ https://doi.org/10.22395/ojum.v18n36a7 \\ Rodrigo Barcia Lehmann" \\ José Maximiliano Rivera Restrepo***
}

\begin{abstract}
RESUMEN
La presente investigación tiene por finalidad analizar el incumplimiento en el soft law a la luz de los nuevos postulados objetivos en torno a la culpa (o lo que se denomina como criterios de imputabilidad objetivos). Las conclusiones ponen en tela de juicio que realmente exista una gran diferencia en cuanto al incumplimiento y la culpa en el sistema de derecho de remedios del soft law, y lo que se ha denominado como derecho tradicional de los contratos. Se revisarán ciertos textos de soft law que han contribuido a cambiar el paradigma en la Europa continental y en América Latina, pasando de un sistema basado en la culpa subjetiva a una noción de culpa objetiva que influye en el cumplimiento específico y en la indemnización de perjuicios. El método de trabajo propuesto es el propio de las ciencias jurídicas: el análisis exhaustivo de doctrina y jurisprudencia, principalmente españolas.
\end{abstract}

Palabras clave: derecho de remedios; responsabilidad objetiva; incumplimiento; soft law; criterio de imputabilidad objetivo.

\footnotetext{
Este trabajo es fruto de la labor de investigación realizada conjuntamente por los académicos autores del mismo.

"* Abogado, licenciado en Ciencias Jurídicas y Sociales, Universidad Central de Chile, MBA Economía y Dirección Internacional de Empresas, MEDI, Universidad Autónoma de Madrid, European Master in Law and Economics, Complutense und Hamburg Universität, doctor en Derecho Privado. Dirección postal: Pedro de Valdivia n. 1509, Providencia, Santiago de Chile. Correo electrónico: rbarcia@uft.cl

***Abogado, licenciado en Ciencias Jurídicas y Sociales de la Universidad de Chile y magíster en Derecho, con mención en Derecho Privado por la Universidad de Chile, máster universitario en Derecho Privado por la Universidad Complutense de Madrid, doctor en Derecho Civil por la Universidad Complutense de Madrid, España. Notario público, conservador de bienes raíces, de comercio, minas y archivero judicial suplente de Tocopilla, profesor de Derecho Civil en la Universidad San Sebastián. Dirección postal: Bellavista n. 7, Piso 7, Recoleta, Santiago de Chile. Correo electrónico: jose.rivera@uss.cl
} 


\section{In what sense is the notion of non-compliance with soft law objectively into the contractual law?}

\section{ABSTRACT}

This research aims to analyze the non-compliance in the soft law, in the light of the new objectives postulates about the guilt (or what has been called as objective criteria of accountability). Conclusions put into question that really there is a big difference in terms of failure and guilt in the system of law of remedies of soft law and what has been called as a traditional contract law. Review of soft law texts, which have contributed to change the paradigm in continental Europe and Latin America, moving from a system based on the subjective guilt to a notion of objective fault influencing specific performance and compensation of damages. The method of work proposed is that of the legal sciences: the exhaustive analysis of doctrine and jurisprudence, mainly Spanish.

Keywords: right of remedy, objective liability, non-compliance, soft law, objective criteria of accountability.

\section{Em que sentido a noç̃o de incumprimento do soft law é objetiva?}

\section{RESUMO}

A presente pesquisa tem por finalidade analisar o incumprimento no soft law à luz dos novos postulados objetivos em torno da culpa (ou o que se denomina como critérios de imputabilidade objetivos). As conclusões põem em causa que realmente existe uma grande diferença com respeito ao incumprimento e à culpa no sistema de direito de soluções do soft law e o que é denominado como direito tradicional dos contratos. Certos textos do soft law que contribuíram para mudar o paradigma na Europa continental e na América Latina serão revisados, ao passar de um sistema baseado na culpa subjetiva para uma noção de culpa objetiva que influencia no cumprimento específico e na indenização de prejuízos. O método de trabalho proposto é o próprio das ciências jurídicas: a análise exaustiva de doutrina e jurisprudência, principalmente espanholas.

Palavras-chave: direito de soluções; responsabilidade objetiva; incumprimento; soft law; critério de imputabilidade objetivo. 


\section{INTRODUCCIÓN}

En la presente investigación se analizarán sucintamente los nuevos postulados planteados por la doctrina referentes a lo que se denomina como soft law. El soft law configura un estatuto jurídico sistematizado sobre el derecho uniforme en distintas áreas, que si bien -en la mayoría de los casos- no son obligatorios se incorporan al derecho interno vía dogmática jurisprudencial. El soft law tiene su origen en ciertos esfuerzos privados de sistematización, unificación y armonización del derecho de las obligaciones y contratos (aunque también existe en otras áreas del derecho, como derecho de familia, responsabilidad de daños, etc.). Sin embargo, su innegable interés doctrinal no solo proviene de ser aplicado por los tribunales de justicia europeos, como si se tratase de verdaderas leyes internas, sino por su innegable valor científico. De este modo, el soft law refleja una actualización del derecho en torno al reconocimiento general de ciertas tendencias imperantes, pero también ha llevado a la creación de concepciones estatutarias propias en cada área del derecho privado. Y en el estatuto contractual una de sus manifestaciones es la llamada objetivación del incumplimiento contractual. En el presente trabajo se revisará el cambio de paradigma que en Europa continental y en la América Latina se está verificando, para sustituir el sistema de la responsabilidad contractual basada en la culpa o dolo del deudor. El nuevo estatuto planteado por el soft law da lugar a un sistema en que el incumplimiento se plantea como objetivo, esto es, que prescinde de la culpa o el dolo. Como se verá, ello solo sucede respecto de la resolución del contrato, no siendo del todo efectivo respecto del cumplimiento específico, ni de la indemnización de perjuicios.

Ahora bien, antes de entrar al tema principal de esta investigación, conviene revisar brevemente qué se entiende por la noción de soft law. Aunque se reconoce que el término soft law fue introducido al lenguaje del derecho internacional por Lord McNair, lo cierto es que este acuñó el término para distinguir entre proposiciones de lege lata y de lege ferenda y no para distinguir un fenómeno complejo que supone la existencia de variaciones normativas que van desde lo no vinculante hasta lo vinculante, del "no derecho" al derecho, de lo soft a lo hard (Del Toro, 2006).

La expresión soft law, también denominada derecho blando, derecho flexible o pre-derecho, es bastante imprecisa, así como el rol que desempeña en el sistema de producción de normas. Cabe aclarar que en su origen no estaba asociada exclusivamente al ámbito internacional, pero ha sido en esta esfera donde alcanzó un mayor fundamento dogmático. No obstante, su configuración actual derivada del derecho internacional y, en particular, de las organizaciones internacionales, ya era conocida en el derecho romano bajo el nombre de lex imperfecta (Boretto, 2012). 
Por tanto, cuando se utiliza la expresión soft law, se está haciendo alusión a todos aquellos esfuerzos, privados o públicos, que han intentado otorgar luces, presentando un texto de derecho uniforme o estatutario que presenta soluciones jurídicas novedosas en diversas materias del derecho contractual. El soft law pretende mejorar la sistematización del derecho privado. De estos textos, hay que aclarar que la Convención de Viena sobre Contratos de Compraventa Internacional de Mercaderías (en adelante CIGS), constituye un tratado internacional. Y es precisamente por ello que goza de fuerza obligatoria, cuestión de la que carece el soft law. Sin embargo, esta convención representa el esfuerzo estatutario inicial sobre el que se construye el soft law europeo de los contratos. Con todo, la autoridad de estos textos privados es tan fuerte que ellos han sido adoptados por los tribunales, tal como si se tratasen de verdaderas leyes.

Para finalizar, a la noción objetiva del incumplimiento en los contratos y a la noción de contrato en general se le opondrá, en este trabajo, lo que se denominará como derecho tradicional. Dicho derecho se basa en una noción del contrato que se sustenta en el pacta sunt servanda, por el cual el acreedor tiene un derecho principal al cumplimiento específico, y uno supletorio a la resolución y la indemnización de perjuicios. Y los derechos supletorios no se basan en el solo incumplimiento, sino que exigen un juicio de imputabilidad axiológico a título de culpa o dolo respecto del deudor.

Esta es la noción del contrato de la Ilustración, y en parte del derecho canónico, que iría un poco más allá en el desarrollo de los derechos del acreedor, conforme al derecho romano, al incorporar la resolución que requería de un pacto comisorio, a través de la condición resolutoria tácita. Sin embargo, no se puede dejar de lado que esta forma de ver el incumplimiento tributa a una noción de contrato que el derecho moderno ha abandonado. Así, el derecho tradicional pondría su acento en el subjetivismo contractual -que fue todo un avance frente al formalismo propio del derecho clásico-. Para el Derecho de la Ilustración la voluntad y el consentimiento son la fuente creadora del derecho subjetivo del acreedor (principio de la libertad para contratar, consensualismo o libertad de forma) y es el consentimiento es la forma exclusiva y preferente de determinación del contenido del contrato (principio de la libertad contractual).

Esta noción del contrato ya se revisó hacia fines de la Ilustración por los pandectistas, dando lugar a concepciones objetivas en materia de efectos de los contratos. Son precisamente estas nociones las que comenzarían a desarrollar el derecho moderno de los contratos. Estas teorías se desarrollaron a través del principio de la buena fe, y dieron lugar a concepciones estatuarias y objetivas de los efectos de las obligaciones. 
Para el efecto de este trabajo esta concepción del contrato se denominará como concepción moderna o actual del contrato, -ya ubicados temporalmente en la sociedad posmoderna- y se diferenciará de la visión meramente subjetiva del contrato. Finalmente, esta concepción daría lugar a lo que se ha denominado como derecho de remedios, dentro del cual está inserto el soft law. Y una de las virtudes del soft law es que tiene una noción del contrato que, sin desconocer la tradición de la Ilustración, es más científica, objetiva y estatutaria. La noción del contrato, no solo se configura por el consentimiento, sino que también estaría dada por un intercambio de expectativas entre las partes. Y esta noción "objetiva" del contrato, como intercambio de expectativas de las partes, determina su estatuto regulatorio en torno a sus efectos y, naturalmente, respecto del incumplimiento.

\section{CONCEPCIÓN OBJETIVA DE INCUMPLIMIENTO}

La doctrina civil está de acuerdo en que no resulta extraño que la comisión de estudios, que dio lugar a los Principles of European Contract Law (en adelante PECL), no haya recepcionado el sistema alemán tradicional en materia de incumplimiento contractual. Ello desde que dicho sistema presenta como desventaja el estar elaborado sobre la base del concepto de imposibilidad, a partir del cual se enuncian y desarrollan una serie de supuestos. Este sistema es de raigambre romana, y en el siglo XIX había sido elaborado por Mommsen, a partir de la stipulatio romana (obligationes stricti iruis) (Möslein, 2010). Por el contrario, el derecho moderno se remonta a los contratos consensuales, como la compraventa, que se estructuraron sobre la base de los principios del consensualismo y la buena fe. La cuestión más importante era establecer bajo qué criterios la indemnización de daños y perjuicios podía ser atribuida al contratante incumplidor, cuestión que el Code francés basa en un concepto unitario de inejecución.

En cambio, tanto en el common law como en los sistemas jurídicos escandinavos, existe una proposición que abarca todas las formas de incumplimiento (non-performance). Esta noción, a partir de Rabel que la incorporó a la CIGS, se extendería a los Países Bajos, los Principios Unidroit y los PECL. Este concepto básico se denomina tekortkoming en el derecho holandés; Pflichtverleztung en el Proyecto de la Comisión de Reforma del Derecho de Obligaciones en Alemania y non-performance en los Principios Unidroit y en los PECL (Zimmermann, 2000). La pregunta que surge a partir de estas nociones de incumplimiento es: ¿cuál es el criterio que califica al incumplimiento contractual? La culpa o negligencia del deudor, bajo el prisma del derecho tradicional, es la que determina la concurrencia de la resolución y la indemnización de perjuicios. Así, la indemnización de daños y perjuicios no opera cuando el daño deriva de una situación ajena a la voluntad del deudor o que este no pudo razonablemente prever al tiempo de celebrar el contrato. Ahora bien, los PECL definen el incumplimiento en los siguientes términos: 
Artículo 1:301: Definiciones. En los presentes principios y salvo que el contexto requiera otra cosa: (4) El término «incumplimiento» denota cualquier incumplimiento de una obligación derivada del contrato, esté o no justificado, e incluye el cumplimiento tardío o defectuoso, así como la inobservancia del deber de colaborar para que el contrato surta plenos efectos.

A su vez, el artículo 8:101 agrega que:

Medios de protección del crédito: (1) Siempre que una parte no cumpla con alguna de las obligaciones derivadas del contrato y el incumplimiento no pueda justificarse con arreglo al artículo 8:108, el perjudicado puede recurrir a cualquiera de los medios dispuestos en el capítulo 9. (2) Cuando el incumplimiento de una de las partes pueda justificarse con arreglo al artículo 8:108, el perjudicado puede recurrir a cualquiera de los medios dispuestos en el capítulo 9, excepto la pretensión de cumplimiento y la indemnización por daños y perjuicios. (3) La parte no puede recurrir a los medios dispuestos en el capítulo 9 en la medida en que haya provocado el incumplimiento de la otra parte.

La doctrina ha caracterizado el incumplimiento como objetivo por cuanto es indiferente si es excusable, el retraso configura incumplimiento, también comprende el incumplimiento defectuoso y el acreedor puede incidir en el incumplimiento por falta de cooperación. Así, para Palazón (2014), los PECL acogen un concepto unitario y objetivo de incumplimiento.

En los PECL, el contratante cumplidor dispone de cinco remedios: (1) el cumplimiento forzado o específico; (2) la resolución del contrato; (3) la suspensión de cumplimiento de su prestación; (4) la indemnización de daños y perjuicios y (5) la reducción del precio. Se debe señalar que el acreedor puede optar por cualquiera de estos cinco remedios. Así lo establece el artículo 4:119 en los siguientes términos: "Acciones para casos de incumplimiento: La parte que tenga derecho a ejercitar alguna de las acciones de este capítulo en circunstancias que le den también derecho a aplicar acciones para casos de incumplimiento, puede utilizar cualesquiera de dichos medios".

Sin perjuicio de lo cual, los PECL se inclinan por la indemnización de perjuicios como derecho preferente, dado que, a pesar de que tiene causales de exclusión aplicable a ambos remedios (artículos 8:108 y 8:101 (2) PECL), establecen causales de exclusión exclusivos para el cumplimiento específico, que no operan respecto de la indemnización de perjuicios (artículo 9:102 (2) y 9:101 PECL) (Barcia, 2017).

Los Principios Unidroit (artículo 7.1.1) establecen que la falta de cumplimiento comprende el incumplimiento total o parcial, defectuoso y, comprende el incumplimiento excusable o no. Al igual que los PECL, se consagra como excusa de incumplimiento la fuerza mayor (artículo 7.1.7), y el hecho impeditivo del acreedor (artículo 7.1.2), que 
es tratado en los PECL como falta de cooperación con el cumplimiento (artículos $1: 202$ y 1:301 (4)).

Finalmente, el Anteproyecto de la Academia de Pavía adopta unos parámetros opuestos a los PECL y los Principios Unidroit. El Anteproyecto parte de una noción unitaria de incumplimiento, pero, luego, detalla supuestos específicos de incumplimiento. No existe incumplimiento si la no realización de la prestación se debe a un cambio de circunstancias que la convierte en excesivamente onerosa y, además, se regula con mayor detalle la mora del acreedor, la cual presupone cualquier conducta que impide la realización de la prestación.

\section{EL INCUMPLIMIENTO DEL CONTRATO EN EL SOFT LAW}

En el presente trabajo pone en tela de juicio que el derecho de remedios constituya una respuesta casi objetiva al incumplimiento, que se plasmaría como un conjunto de opciones a las que puede recurrir el acreedor. En este sentido, a pesar que Díez-Picazo, Roca, Trías y Morales (2002), señalan que la culpa, como reproche a la conducta del deudor, es ajena a los PECL, la cantidad de excepciones al cumplimiento a lo menos nos llevan a entender que existe un criterio de exculpabilidad objetivo. Así, los referidos autores se refieren a los tres criterios exoneratorios del artículo 8.108 (1). Miquel (2008) en los siguientes términos:

Los principios siguen un concepto de culpa que corresponde a la opinión dominante en la mayoría de los ordenamientos europeos (hay nota al pie), es decir, una noción de culpa objetiva $u<<$ objetivada $>>$ que adopta como criterio un estándar de conducta objetivo al cual todos deben adaptarse, independientemente de sus capacidades individuales y que, puede afirmarse, no tiene ya nada que ver con el reproche culpabilístico" (lo destacado entre paréntesis es nuestro).

Así, existe una noción de excusabilidad determinado por la exclusión de reproche en la medida que las circunstancias que alega el deudor obedezcan a un estándar normativo entendido de forma objetiva. Esta forma de ver la imputabilidad no es del todo ajena a asimilar las causas de eximición a la fuerza mayor y la exclusión de culpa del deudor. Ello naturalmente estaría dado por una concepción objetiva de la culpa. De este modo la doctrina señala como ejemplos de estas formas de exclusión en la aplicación de los remedios la expropiación, la extracomercialidad sobrevenida, la prohibición de la autoridad, etc. Así, se podría comprender como causa eximente la excesiva onerosidad de la prestación por aplicación del artículo 6:111 PECL, por cuanto la ejecución forzada no opera en la medida que el cumplimiento se haya hecho más oneroso. En este sentido, en el trabajo colectivo de la Asociación Henri Capitant (2008) se señala: 
Since PECL choose, in contrast to some national laws (see infra), to admit the revision of the contract in the case of unforeseeable change of circumstances, it is important that the guiding principle dedicated to the principle of binding force itself states this limit to the intangibility of the contract. It is posible to envisage a concept of 'unforseeable change of circumstances' since it si defined by Article 6:111'.

De este modo, el cumplimiento excesivamente oneroso podría operar como causa eximente, a pesar de que los PECL no recurren a criterios objetivos para su delimitación. En igual sentido para Zimmermann (2000) si el incumplimiento se encuentra justificado, declina la indemnización de perjuicios y el cumplimiento forzado. Es interesante señalar que la jurisprudencia española ha acogido lo establecido por los PECL, los que, como se dijo, sin ser obligatorios para los tribunales españoles, les han servido a los jueces para orientar sus sentencias y constituyen un claro ejemplo de soft law. Así, por ejemplo, la sentencia del Tribunal Supremo español n. ${ }^{\circ}$ 4628/2016, de 24 de octubre, dispone que:

En el presente caso, no cabe duda de que la comercializadora, como suministradora, se vinculó contractualmente a una obligación de suministro de energía de acuerdo a unos estándares de calidad y continuidad del suministro (cláusula 1.1 del contrato). Del mismo modo que se reservó, como condición suspensiva del contrato, una facultad de control acerca de la adecuación de las instalaciones del cliente para que dicha energía pudiera ser suministrada (cláusula 1.4 del contrato). Por su parte, el cliente accedió a dicha contratación confiado en que del contrato suscrito podría razonablemente esperar, a cambio del precio estipulado, que la comercializadora respondiera de su obligación, no como una mera intermediaria sin vinculación directa, sino que cumpliese con las expectativas de «todo aquello que cabía esperar» de un modo razonable y de buena fe, con arreglo a la naturaleza y características del contrato celebrado. Integración contractual, con base al principio de buena fe, que también viene contemplada en el artículo 6:102 PECL (Principios de derecho europeo de los contratos). Como tampoco puede concebirse como caso fortuito exonerador de responsabilidad (artículo 1105 del Código Civil) un suceso que cae dentro de la esfera de control de riesgo a cargo del deudor, y al que es ajeno el cliente o consumidor.

De esta forma, el acreedor puede optar entre los diferentes remedios. En el derecho tradicional el concepto sobre el que se articulan los efectos de las obligaciones, frente al incumplimiento, es la culpa (salvo, en parte, respecto del cumplimiento específico que no requiere de culpa). El deudor se hace responsable en la medida que ha incumplido su obligación con culpa. La culpa, asimismo, se exige no solo en la indemnización de perjuicios, sino también es un presupuesto de la resolución. Por ello es que el derecho principal del acreedor será el cumplimiento forzado. Este derecho

1 Desde que el PECL escoge, en contraste con algunas leyes nacionales (ver infra), para admitir la revisión del contrato en el caso de cambio de circunstancias imprevisibles, es importante que el principio rector de la fuerza vinculante (del contrato) conforme a su propio estatuto señala este límite a la intangibilidad del contrato. Es posible concebir un concepto de "cambio de circunstancias imprevisibles", puesto que si se definen en el artículo 6:111. 
siempre asiste al acreedor y, en principio, es ajeno, a la culpa. Ello, a pesar de que, la ausencia de culpa opera como causal de extinción de la obligación -como sucede en el caso fortuito o fuerza mayor y, eventualmente, en el estado de necesidad-. La culpa, como elemento de la responsabilidad civil, tuvo su origen en el tratamiento que el derecho romano dispensó a la inejecución de las obligaciones, pero debiéndose, además, complementar con el daño para generar la obligación indemnizatoria. Pero, en los delitos y cuasidelitos no era la culpa la que generaba la responsabilidad, pues ni en la Ley de las XII Tablas ni en la Ley Aquilia era computable para la determinación de la responsabilidad del autor del daño y de la consiguiente obligación de resarcirlo o repararlo, ya que bastaba solo la existencia del daño (Vidal Ramírez, 2001; Barcia, 2007).

Sin perjuicio de lo cual, para parte de la doctrina española, en materia de responsabilidad civil -contractual y extracontractual-, el sistema tradicional de la culpa ha dado lugar a la responsabilidad por riesgo (Clemente, 1998; Kubica, 2015). En este sentido, el deudor, dependiendo de la posición que el ordenamiento jurídico adopte, podrá alegar el caso fortuito para oponerlo al cumplimiento forzado, que operará necesariamente respecto de su propia obligación, como por ejemplo sucede respecto de la obligación de entregar en la compraventa. En este último caso, respecto de la obligación correlativa en que el acreedor es el deudor, se plantea el problema de la teoría de los riesgos. En España, se ha dicho que, tratándose de las obligaciones de resultado, el coeficiente de atribución es objetivo. No se analiza el comportamiento del incumplidor para calificar su inobservancia (Rivera, 2016a; Vélez, 2012), por tanto, el acreedor podrá recurrir a los remedios que sean aplicables. Sin embargo, también la solución puede plantearse desde los principios del pago, como se hace en el derecho alemán. Así, la reforma del 2012 de las obligaciones mantendría reglas especiales para el incumplimiento en materia de imposibilidad en la ejecución. Y ello se evidencia, por ejemplo, respecto de la obligación de desarrollar un complejo programa computacional contratado por una empresa. Supongamos que la empresa, encargada del programa, lo entrega, pero que su contraparte estima que dicha entrega no cumple con lo solicitado. Se puede apreciar que estos casos son de difícil solución para el derecho tradicional, que en estos casos recurre a las reglas de la compraventa. En dicho derecho se habría cumplido con la entrega, pero "la cosa" entregada adolecería de un vicio oculto. Sin embargo, como en realidad se trata de un servicio, es decir, de una obligación de hacer, no es claro si el estándar -respecto de una eventual demanda de incumplimiento imperfecto o derechamente de incumplimiento- se adscribe a lo convenido, es decir, a las reglas del pago, o es posible aplicar los estándares de culpa de la responsabilidad civil, y que son propios de la responsabilidad civil. Acá vemos otra vinculación entre cumplimiento y culpa, que no es del caso desarrollar en la presente investigación. En el derecho tradicional, el incumplimiento culpable da lugar a los derechos supletorios. Así, en España, para Gómez (2007) "la noción 
de incumplimiento puede entenderse como la resultante de combinar dos elementos conceptualmente diversos: la materialidad del incumplimiento o falta de cooperación -en amplio sentido- del contratante y la imputación de tal incumplimiento a una de las partes contractuales".

A su vez, Díaz Tolosa plantea que en Chile, "la responsabilidad civil está inspirada en los principios clásicos -consagrados en el Código Civil decimonónico-y, por ende, el fundamento del deber de reparar un daño, reside en la conducta subjetiva -dolosa o culposa- del autor del mismo" (2007).

En las concepciones literales del contrato, propias del derecho tradicional, la única eximente valedera al cumplimiento es el caso fortuito o la fuerza mayor. Aunque también excluye el cumplimiento forzado, la imposibilidad de cumplimiento o de ejecución del contrato, como si el vendedor ha enajenando la cosa a un tercero. Naturalmente, esta eximente se ha hecho muy relevante desde que en Chile, como en la mayoría de los países, no se admite la prisión por deudas. La prisión por deudas fue suprimida por el Decreto con Fuerza de Ley de 8 de febrero de 1837, sobre procedimiento ejecutivo y concurso de acreedores, que se enmarca dentro de las llamadas "Leyes Marianas" se procedió a suprimir la prisión por deudas (Bravo,1983).

La tesis literalista del contrato está unida a una noción subjetiva de la culpa, que el derecho de remedios, inspirándose en el derecho moderno de los contratos, ha comenzado a desechar. Este ha sido un largo proceso que comenzó con una visión crítica de las teorías subjetivas, que tiene su origen en los pandectistas.

De esta forma todo el análisis objetivo de la culpa, con relación al cumplimiento, se hace a través de lo que podemos denominar como imposibilidad de cumplimiento. A este respecto, se aprecia que el derecho moderno no tiene grandes diferencias con el soft law, aunque el derecho tradicional rechaza los criterios objetivos de exclusión de cumplimiento, como el precedentemente planteado. En este sentido, la forma en que opera el cumplimiento en el derecho moderno y en el soft law se diferencia en cuanto al incumplimiento. Así, el incumplimiento para el derecho tradicional lleva necesariamente al cumplimiento específico, salvo caso fortuito o fuerza mayor. En cambio, el derecho moderno y el soft law incorporan una forma de exclusión o revisión objetiva de incumplimiento, que se aleja de la concepción del contrato del pacta sunt servanda.

Tampoco se aprecia una gran diferencia entre cumplimiento forzado y la indemnización de perjuicios en el derecho tradicional. Ella no es de la entidad que se supone, toda vez que, para efectos de la indemnización de perjuicios, en el derecho tradicional, el incumplimiento se presume culpable. Incluso en el derecho tradicional, como se analizó, las posibilidades de eximir el cumplimiento se reducen al caso fortuito o fuerza mayor. De esta forma, las eximentes de cumplimiento son más restrictivas 
en el derecho tradicional que en el derecho moderno. Por tanto, en realidad entre cumplimiento forzado e indemnización de perjuicios no existirían grandes diferencias en torno a sus presupuestos de aplicación, salvo una de relevancia: en el sistema tradicional, en el cumplimiento forzado, solo la imposibilidad -ya sea por imposibilidad material, como destrucción de la cosa por acto culpable del deudor o caso fortuito, o imposibilidad jurídica, como en los casos de enajenación a un tercero- da lugar a los derechos supletorios. De este modo, el cumplimento se hace imposible en caso que el deudor enajene la cosa a un tercero y, solo en ese caso, el acreedor puede recurrir a los derechos supletorios que le asisten. La gran diferencia entre el sistema tradicional o literalista y el del Derecho de remedios -descartada la diferencia entre derecho principal al cumplimiento, y supletorio a la resolución más la indemnización de perjuicios-, es la forma en que opera la culpa.

En el sistema tradicional, el cumplimiento forzado, por regla general, solo exige incumplimiento, y no culpa, pero la falta de culpa juega como eximente en el caso fortuito o la imposibilidad sobrevenida. En la indemnización de perjuicios aparentemente se exige incumplimiento culposo, pero como la culpa se presume, nuevamente la culpa está regulada como eximente de responsabilidad. Y en este sentido la eximente es la misma: el caso fortuito o la fuerza mayor. El deudor podrá eximirse de la responsabilidad civil, en caso de operar caso fortuito o imposibilidad sobrevenida. Esta diferenciación se diluye aún más en el derecho moderno. Por ello es que, a lo menos formalmente, en el derecho de remedios, el derecho de opción entre las pretensiones de cumplimiento forzado y los otros derechos supletorios coinciden en cuanto a sus supuestos de exigibilidad: operan frente al incumplimiento. En el derecho tradicional no hay un verdadero derecho de opción, desde que el acreedor solo tiene como derecho al cumplimiento forzado. El derecho de opción, en un sentido lato, exige una unidad de condiciones de exigibilidad que el derecho tradicional no tiene. En el derecho tradicional, la imposibilidad en la ejecución es la que permite que el acreedor recurra a los remedios supletorios; pero además el cumplimiento forzado generaba un importante incentivo de cumplimiento, como lo era la prisión por deudas. El derecho opción, entonces, se plantea más bien como un sistema de jerarquización de derechos, en los cuales el derecho principal es el cumplimiento forzado.

En cambio, el derecho moderno y el soft law suponen, como supuesto de exigibilidad general a todo remedio: el incumplimiento, y no imponen una acreditación de la imposibilidad de cumplimiento, como presupuesto fundamental para recurrir a los otros remedios. Sin embargo, no es efectivo que en el soft law el acreedor pueda optar libremente por cualquiera remedio frente al incumplimiento, desde que cada uno exige diferentes presupuestos de exigibilidad (por eso la diferenciación es más formal que real, una vez salvada la diferencia entre derecho principal y supletorio). El que los remedios sean una respuesta general al incumplimiento supone que el siste- 
ma de responsabilidad civil frente al incumplimiento es objetivo, lo que se hace muy difícil en la responsabilidad contractual. Tal vez por ello es tan interesante la posición de Vidal -que de una forma un tanto inconsciente-sostiene que la responsabilidad civil establecida en el artículo 79 CIGS, es objetiva, en contraposición con su maestro que sostiene acertadamente, a nuestro entender, que es un sistema de imputabilidad objetivo (Vidal Olivares, 2006; Morales, 2006), que naturalmente debe ser calificado como de responsabilidad subjetiva. El punto no es menor, por cuanto Vidal entiende que el incumplimiento es netamente objetivo, y por ello concluye que la responsabilidad es objetiva; cuando en realidad se trata de una responsabilidad subjetiva basada en criterios de imputabilidad objetiva.

En este sentido, los PECL crean un espejismo, pues, por una parte señalan en el artículo 9:501 que la indemnización de perjuicios es una consecuencia del incumplimiento, pero agregan que: "este incumplimiento no quede cubierto por la excepción del artículo 8:108", o sea, exigen un criterio de imputabilidad objetiva, esto es, que no opere "un impedimento que queda fuera de su control y que no se puede pretender de manera razonable que hubiera debido tenerse en cuenta dicho impedimento en el momento de la conclusión del contrato o que la parte hubiera debido evitar o superar dicho impedimento o sus consecuencias".

De este modo, los PECL recurren a una concepción objetiva de culpa que es oponible tanto al cumplimiento forzado como a la indemnización de perjuicios. En otras palabras, tal y como ocurre en el derecho tradicional, el cumplimiento forzado y la indemnización de perjuicios, no son una respuesta automática al incumplimiento (Díez-Picazo et al., 2002; Guevara y Mufdi, 2017). A este respecto es importante aclarar que en los PECL las causales de exoneración para la pretensión de cumplimiento y de indemnización de daños y perjuicios son comunes. En este sentido, la solución adoptada en los artículos 8:101 (2) y 8:108 de los PECL, se alejaría de la posición de la CIGS en su artículo 79. Además, la exclusión de la pretensión de cumplimiento e indemnizatoria no impide recurrir a los otros remedios (artículo 8:108), lo que impondría un orden jerárquico a lo menos respecto de los presupuestos de concurrencia del cumplimiento y la indemnización de perjuicios, y los otros remedios contractuales. No ocurre lo mismo en la CIGS. Así, Vidal señala que el artículo 79 (5) CIGS limita la exoneración a la indemnización, dejando subsistentes los otros remedios respecto del incumplimiento (Vidal, 2006). En realidad, su opinión no es del todo exacta por cuanto la doctrina ha hecho esfuerzos por hacer coincidir la causal de exoneración de la indemnización de perjuicios con la del cumplimiento forzado (Morales, 2006). Por tanto, desechada la indemnización de perjuicios, el acreedor puede recurrir a los siguientes remedios: (a) cumplimiento forzado; (b) resolución y (c) reducción del precio. Vidal sostiene esto por aplicación de la normativa de la CIGS (Vidal, 2006); y específicamente por aplicación de sus artículos 45 (1) y 61 (1). 


\section{EL INCUMPLIMIENTO RESOLUTORIO: ABANDONO DE LA NOCIÓN DE BREACH OF THE CONTRACT EN LOS PECL}

La CIGS, los PECL y los Principios Unidroit (International Institute for the Unification of Private Law) parten de la distinción entre incumplimiento esencial y no esencial del contrato, inspirado a su vez en la distinción entre fundamental breach y non-fundamental breach del derecho anglosajón. El concepto de incumplimiento es genérico e integra la inobservancia de cualquier obligación derivada del contrato (cumplimiento defectuoso, tardío, incluso infracción de deberes accesorios). Esta distinción se revela especialmente útil en sede de CIGS dado que solo cabe resolver el contrato en caso de incumplimiento esencial (artículo 25 CIGS). Este criterio está conforme con el principio del favor negotti (Marsal y Lauroba 2003; Rivera, 2016b; Rivera, 2016c; Rivera, 2017a; Rivera, 2017b; Rivera, 2017c; Rivera, 2017d; Rivera, 2017e).

La calificación de un incumplimiento como fundamental se sustenta en la tesis inglesa del breach of the contract y es la base en la CISG para poder establecer los remedios a dicho incumplimiento. El texto del artículo 25 nos lleva a destacar los siguientes rasgos del incumplimiento: (i) interpretando la literalidad de las palabras, tenemos que debe tratarse del incumplimiento de una obligación contractual, (ii) el incumplimiento de la obligación debe causar perjuicio, (iii) el acreedor debe haberse visto privado sustancialmente de lo que tenía derecho a esperar del contrato, (iv) las consecuencias del incumplimiento no deben haberse podido prever. Sin embargo, la doctrina distingue entre la CIGS y los PECL, a este respecto, por cuanto en el primer instrumento se habría optado por seguir la noción de breach of contract, en cambio, en el segundo se habría distinguido entre non-performance y performance conforme al artículo 8:101 PECL (Martínez, 2003).

El incumplimiento esencial del contrato produce el efecto principal de otorgar al acreedor el derecho a resolver el contrato en su totalidad. En este supuesto, solo será necesario comunicar la resolución a la contraparte, sin necesidad de que medie una instancia judicial (artículo 9:303 (1) PECL). La declaración debe ser clara, incondicional e irrevocable. La declaración unilateral del perjudicado, que genera la resolución, cumple una función restitutoria separada de la noción de culpa. En torno al tema que nos interesa, la objetivación del incumplimiento supone que, frente a un incumplimiento por caso fortuito o fuerza mayor, igualmente procede la acción resolutoria, pero con una diferencia: no es posible pedir también una indemnización de daños y perjuicios (Palazón, 2014).

En igual sentido en España, la Sentencia del Tribunal Supremo de 14 de diciembre de 1998, estableció una opinión mixta, conforme a la cual se decretó que, frente al caso 
fortuito o fuerza mayor, existe igualmente derecho a pedir la resolución del contrato, pero con una salvedad: no es posible solicitar también una indemnización de daños y perjuicios (Méndez y Vilalta, 2002). En otras palabras, el caso fortuito supone un problema de inimputabilidad, que afecta a la indemnización de perjuicios, pero no a la resolución del contrato.

Otro factor relevante a considerar es el elemento tiempo, puesto que la declaración será efectiva desde el momento de la recepción de la misma por la otra parte. Teniendo en consideración las graves consecuencias que trae aparejada la declaración, se establece que la parte perjudicada por el incumplimiento perderá el derecho a declarar resuelto el contrato si no realiza la declaración precedente en un plazo razonable. La determinación exacta de este plazo deberá ser apreciada jurisprudencialmente en virtud de las circunstancias concretas. El artículo 8:103 PECL define el incumplimiento esencial en los siguientes términos:

El incumplimiento de una obligación es esencial para el contrato: (a) cuando la observancia estricta de la obligación pertenece a la causa del contrato, (b) cuando el incumplimiento prive sustancialmente a la parte perjudicada de lo que legítimamente podía esperar del contrato, salvo que la otra parte no hubiera previsto o no hubiera podido prever en buena lógica ese resultado, (c) o cuando el incumplimiento sea intencionado y dé motivos a la parte perjudicada para entender que ya no podrá contar en el futuro con el cumplimiento de la otra parte.

A este respecto, la doctrina española destaca que lo que hace que el incumplimiento sea esencial no es su gravedad, sino la afectación de lo acordado y las expectativas resultantes (Díez-Picazo et al., 2002). La referencia al incumplimiento esencial es más tenue en los Principios Unidroit (artículos 7.1.5 (3) y 7.3.1 (2)), y excluye el incumplimiento mínimo (artículo 7.1.5 (4)); pero aún de producirse un incumplimiento esencial el deudor puede subsanar el incumplimiento conforme a lo establecido en el artículo 7.1.4 (Díez-Picazo et al., 2002).

\section{CONCLUSIONES}

La gran diferencia entre el soft law y el derecho moderno de los contratos, por una parte, y el derecho tradicional, por la otra, es el rechazo del pacta sunt servanda como principio determinante de los derechos del acreedor frente al incumplimiento. La concepción tradicional plantea que el acreedor respecto del cumplimiento específico solo exige incumplimiento del deudor, salvo caso fortuito o fuerza mayor, y que, respecto de la resolución y la indemnización de perjuicios, como derechos supletorios de menor entidad, se exige además culpa del deudor. Ya se ha analizado que esta distinción ni siquiera es real en el derecho tradicional, desde que el caso fortuito y la fuerza mayor afectan tanto al cumplimiento, como a la resolución del contrato con indemnización 
de perjuicios por igual. Además, la exigencia de un juicio de culpabilidad respecto del deudor, en la indemnización de perjuicios, es más bien ilusoria que real desde que el incumplimiento se presume culpable.

El concepto objetivo de incumplimiento, propio del derecho moderno y del soft law, no da lugar a que el acreedor necesariamente pueda hacer uso de cualquier remedio contractual. Ello dependerá de los presupuestos de procedencia de cada remedio que alteran la referida concepción objetiva de incumplimiento. No es que se desconozca que el derecho a opción del acreedor se determina conforme a concepciones que no se abordan en el presente trabajo, como la buena fe o la razonabilidad; pero el incumplimiento no es un presupuesto disociado de la culpa o su ausencia desde que el caso fortuito y la fuerza mayor operan como eximentes, sino que además está vinculado a ella desde una noción objetiva de falta de culpa (que se determina, conforme a lo que se ha analizado, a criterios de imputabilidad objetiva), y que es ajena al derecho tradicional. Así se desprende de la aplicación de los artículos 6:111 y 108 PECL, que van más allá del caso fortuito y la fuerza mayor. Por ello es, precisamente, que el incumplimiento exige un juicio de imputabilidad o inimputabilidad objetivo -tanto respecto del cumplimiento, como de la indemnización de perjuicios- que hace que la noción objetiva de incumplimiento, como una transgresión a lo convenido en el contrato, tambalee. Ciertamente, que este juicio de imputabilidad e inimputabilidad es objetivo. En materia de indemnización de perjuicios, da lugar a una responsabilidad civil subjetiva y en materia de cumplimiento al análisis de la imposibilidad en la ejecución; pero del análisis precedente se desprende que la imputabilidad está íntimamente ligada al incumplimiento en ambos remedios. Sin perjuicio de lo anterior, la resolución en el derecho moderno y el soft law -a diferencia del derecho tradicional, que exige culpa-, se presenta totalmente disociada de cualquier criterio de imputabilidad y, en este estadio, el incumplimiento se presenta como una transgresión del contrato ajeno a cualquier criterio de imputabilidad. Pero, aún en este caso, el mero incumplimiento no basta, pues se exige que este sea esencial.

\section{REFERENCIAS}

Association Henri Capitant des Amis de la Culture Juridique Francaise and Société de Législation Comparée (2008). European Contract Law. Materials for a Common Frame of Reference: Terminology, Guiding Principle, Model Rules. Munich: Sellier, European Law Publishers.

Barcia Lehmann, R. (2007). La asimilación de la culpa al dolo desde una perspectiva objetiva del derecho de los contratos: segunda parte. Ius et Praxis, 13(1), 29-44.

Barcia Lehmann, R. (2017). Una revisión del «ius electionis» en el denominado derecho de remedios. Estudios de Derecho Civil XII (pp. 453-464). Santiago de Chile: Thomson Reuters.

Boretto, M. (2012). Soft law. Nuevos enfoques para el desarrollo progresivo del derecho internacional de la propiedad intelectual. Ars Boni et Aequi, 8(2), 81-144. 
Bravo Lira, B. (1983). Los comienzos de la codificación en Chile. Revista Chilena de Historia del Derecho, 9, 191-210.

Clemente Meoro, M. E. (1998). La facultad de resolver los contratos por incumplimiento. Valencia: Tirant lo Blanch.

Comisión de las Naciones Unidas para el Derecho mercantil internacional. (2011). Convención de las Naciones Unidas sobre los Contratos de Compraventa Internacional de Mercaderías. Nueva York: Publicaciones y Biblioteca, Oficina de las Naciones Unidas en Viena.

Del Toro, L. (2006). El fenómeno del soft law y las nuevas perspectivas del derecho internacional. Anuario Mexicano de Derecho Internacional, VI, 513-549.

Díaz Tolosa, R. I. (2007). Responsabilidad objetiva en el ordenamiento jurídico chileno. Revista de Derecho de la Universidad Católica del Norte, 14(1), 79-112.

Díez-Picazo, L., Roca, I., Trías, E. y Morales Moreno, A. M. (2002). Los principios del derecho europeo de contratos. Madrid: Civitas.

España. Tribunal Supremo. Sala de lo Civil. (2016). STS 4628 de octubre 24. Recuperado de http:// www.poderjudicial.es/search/openDocument/839cbb18f55d533c

Guevara Parra, V. y Mufdi Guerra. M. (2017). La evolución del concepto de contrato y su incidencia en los principales mecanismos de protección del acreedor insatisfecho. Santiago de Chile: Universidad de Chile.

Gómez Pomar, F. (2007). El incumplimiento contractual en derecho español. Indret. Revista para el Análisis del Derecho. Recuperado de www.raco.cat/index.php/InDret/article/download/78949/103090

Kubica, M. L. (2015). El riesgo y la responsabilidad objetiva (Tesis doctoral) Universidad de Girona, España. Recuperado de dugi-doc.udg.edu/bitstream/handle/10256/11812/tmlk1del. pdf?sequence $=1$

Marsal Guillamet, J. y Lauroba Lacasa, E. (2003). Algunos mecanismos de protección en caso de incumplimiento contractual en el futuro derecho europeo de contratos. Cumplimiento especifico e indemnización por daños y prejuicios. En A. Cabanillas (Coord.), Estudios Jurídicos en Homenaje al Profesor Luis Diez-Picazo. II (pp. 2455-2470) Madrid: Thomson Civitas.

Martínez Sanz, F. (2003). Principios de derecho europeo de los contratos (Comisión Lando). En S. Cámara Lapuente (Coord.), Derecho Europeo Privado (pp. 193-198). Madrid: Colex.

Méndez, R. M. y Vilalta, A. E. (2002). La resolución contractual. Acción resolutoria en el contrato de compraventa. Barcelona: Bosch.

Miquel Martín (Coord.). (2008). Principios de derecho europeo de la responsabilidad civil. Navarra: ThomsonAranzadi.

Morales Moreno, A. M. (2006). Modernización del derecho de las obligaciones. Madrid: Civitas. 
Möslein, F. (2010). Legal innovation in European contract law: within and beyong the (Draft) Common Frame of Reference. En H.-W. Micklitz y F. Cafaggi (Eds.), European Private Law after the Common Frame of Reference (pp. 173-219) Cheltenham: Edward Elgar Publishing Limited.

Palazón Garrido, M. (2014). Los remedios frente al incumplimiento en el Derecho comparado. Pamplona: Editorial Thomson Reuters Aranzadi.

Unidroit (2010). Principios Unidroit sobre los contratos comerciales internacionales 2010. Recuperado de https:// www.internationalcontracts.net/documentos-derecho-internacional/Principios-UNIDROIT-sobreContratos-Comerciales-Internacionales.pdf

Rivera Restrepo, J. M. (2017a). La gravedad de incumplimiento como requisito del derecho de opción del acreedor. Tendencias modernas. RJUAM, (34), 267-291.

Rivera Restrepo, J. M. (2017b). Marco común de referencia y derecho de opción del acreedor en el incumplimiento contractual. Revista Díkaion, 25(2), 266-288.

Rivera Restrepo, J. M. (2017c). Es necesaria la imputabilidad para que opere el derecho de opción del acreedor. Revista Boliviana de Derecho y Actualidad Jurídica Iberoamericana, (24), 120-139.

Rivera Restrepo, J. M. (2017d). El derecho de opción en Italia. Revista Direito GV, 13(1), 303-333.

Rivera Restrepo, J. M. (2017e). El derecho de opción del acreedor ante el derecho alemán de las obligaciones. Tendencias modernas. Revista Jurídicas, 14(1), 40-53.

Rivera Restrepo, J. M. (2016a). El fundamento del derecho de opción del ante el incumplimiento contractual (condición resolutoria tácita). Foro. Revista de Ciencias Jurídicas y Sociales. Nueva Época, 19(1), 203-244.

Rivera Restrepo, J. M. (2016b). Algunas observaciones acerca del derecho de opción del acreedor ante el incumplimiento contractual, en el common law. Cuadernos de Derecho Transnacional, 8(1), 223-233.

Rivera Restrepo, J. M. (2016c). ¿Es necesaria la mora del deudor para que opere el derecho de opción del acreedor? Revista Jurídica Cajamarca, Derecho y Cambio Social, (45), 1 15.

Unión Europea. (2002). The Principles of European Contract Law. Recuperado de https://www.jus.uio. no/lm/eu.contract.principles.parts.1.to.3.2002/portrait.pdf

Vélez Posada, P. (2012). La responsabilidad civil contractual y extracontractual: el seguro como criterio de imputación. (Trabajo fin de master). Universidad Complutense, Madrid. Recuperado de http://eprints.ucm. es/15867/

Vidal Olivares, A. (2006). El incumplimiento contractual y los remedios de que dispone el acreedor en la compraventa internacional. Revista Chilena de Derecho, 33(3): 468 469.

Vidal Ramírez, F. (2001). La responsabilidad civil. Revista de la Facultad de Derecho, 54. Recuperado de https://dialnet.unirioja.es/descarga/articulo/5084757.pdf

Zimmermann, R. (2000). Estudios de derecho privado europeo. Madrid: Civitas. 